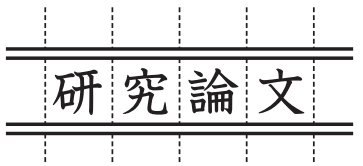

$\mathrm{TiO}_{2}$ 粒子を添加した高強度 $\mathrm{TiNi}$ 形状記憶粉末合金の組織構造と力学特性

\title{
Microstructural and Mechanical Properties of P/M High Strength TiNi Alloy with $\mathrm{TiO}_{2}$ Particles
}

\author{
米澤隆行*・吉村知浩*・梅田純子**・近藤勝義**・早場亮一*** \\ Takayuki YONEZAWA, Tomohiro YOSHIMURA, Junko UMEDA, Katsuyoshi KONDOH and Ryouichi SOUBA
}

(Received August 31, 2012)

\begin{abstract}
Titanium-nickel (TiNi) alloys of near-equiatomic composition are the most popularly commercialized shape memory alloys (SMAs) with excellent characteristics, such as shape memory effect, superelasticity, a high strength, good corrosion resistance and good biocompatibility. Recently, TiNi SMAs with superelastic behavior are used in advanced medical devices, such as guide wire, catheter and stent to restore a damaged blood vessel. Improvement of mechanical and shape memory properties of TiNi SMAs cause a remarkable reduction of wire diameter, and results in a reduction of surgical invasion and an improvement of quality of life (QOL). In this study, microstructural, mechanical and shape memory properties of the extruded and heat-treated TiNi alloys by sintering the mixture of TiNi pre-alloyed powder with titanium dioxide $\left(\mathrm{TiO}_{2}\right)$ particles were investigated. Ti-51.19 at.\% Ni pre-alloyed powder with $\mathrm{TiO}_{2}$ particles were consolidated by spark plasma sintering (SPS) at $1173 \mathrm{~K}$ in vacuum. SPSed TiNi alloy powder compacts were extruded at $1373 \mathrm{~K}$ and shape memory heat-treated at $773 \mathrm{~K}$. Ti ${ }_{4} \mathrm{Ni}_{2} \mathrm{O}$ phase was formed during SPS by reaction between TiNi matrix and oxygen atoms originated from additive $\mathrm{TiO}_{2}$ particles. As a result, the soluted $\mathrm{Ni}$ content in TiNi matrix of the TiNi alloy with 1.0 vol. $\% \mathrm{TiO}_{2}$ particles was increased by 0.78 at.\% compared to the original $\mathrm{TiNi}$ alloy with no $\mathrm{TiO}_{2}$ particle. The tensile and shape memory properties of the heat-treated $\mathrm{TiNi}$ alloy with $1.0 \mathrm{vol} . \% \mathrm{TiO}_{2}$ particles were obtained as follows; an average value of plateau stress: $524 \mathrm{MPa}$, ultimate tensile strength (UTS): $1298 \mathrm{MPa}$, and shape recovery rate when $8 \%$ strain: $89.3 \%$. The heat-treated TiNi alloy with 1.0 vol. $\% \mathrm{TiO}_{2}$ particles revealed the high strength and good shape memory properties. The high strengthening mechanism of the $\mathrm{TiNi}$ alloys with $\mathrm{TiO}_{2}$ particles was mainly due to a decrease martensitic transformation temperature by an increase soluted $\mathrm{Ni}$ content in TiNi matrix after reaction between $\mathrm{TiNi}$ and $\mathrm{TiO}_{2}$.
\end{abstract}

Key Words: Titanium Alloy, Shape Memory Materials, Titanium-nickel, Titanium Dioxide, Powder Metallurgy

\section{1. 緒言}

原子比が $1: 1$ 付近の TiNi 合金は、形状記憶合金として 優れた形状記憶効果や超弾性を発現する ${ }^{1)}$ 。また、TiNi 合 金は、その他の形状記憶合金に比べて形状回復応力が大き いことに加え、耐腐食性や生体適合性にも優れる ${ }^{2), 3) 。 ゆ ~}$ えに、超弾性を利用し、TiNi 合金は非開心・開腹手術に用 いるガイドワイヤーやカテーテル、ステントといったワイ ヤー状の高度医療用デバイスに積極的に利用されている ${ }^{4)}$ TiNi 合金の力学・形状記憶特性の向上は、医療デバイスの 小型・高性能化を実現し、医療のさらなる低侵襲化、なら びに患者の QOL（生活の質、Quality of life）の飛躍的な改 善につながる。TiNi 合金は、Ti と Ni が交互に配列した規 則構造を有する結晶が負荷応力によりマルテンサイト変態 およびその逆変態することによって超弾性を発現する ${ }^{1)}$ 一方、このような特殊な結晶変態に基づく変形機構のため、 $\mathrm{TiNi}$ 合金における力学 · 形状記憶特性の向上に資する材料
設計の自由度は制限され、これまでの実質的な制御方法は、 塑性加工による加工硬化および熱処理による組織制御が主 たる方策であった ${ }^{5)}$ 。そこで、本研究では固相法を基調と した粉末治金プロセスを用いて、 $\mathrm{TiO}_{2}$ 粒子添加による $\mathrm{TiNi}$ 母相での固溶 Ni 量の間接的制御、ならびに TiNi 焼結合金 の力学・形状記憶特性の制御手法の確立を目指す。本報で は、 $\mathrm{TiNi}$ 合金粉末に $\mathrm{TiO}_{2}$ 粒子を添加し、固化焼結後に熱間 押出加工および形状記憶熱処理を施すことで組織・組成制 御を行った。添加した $\mathrm{TiO}_{2}$ 粒子は、粉末焼結過程において TiNi 相母相と反応することで Ti-rich な Ti-Ni-O 系化合物を 生成すると考えられる ${ }^{6,7)}$ 。また、Ti-rich な酸化物の生成に 伴い TiNi 母相における固溶 $\mathrm{Ni}$ 量が増加することが期待で きる。そこで、生成した酸化物および TiNi 母相の固溶 Ni 量増加による力学・形状記憶特性への影響を明らかにする ため、作製した試料の組織構造および力学・形状記憶特性 について調査した。また、これらの調査結果に基づき、本 試料における高強度発現機構に関して考察を行った。

*大阪大学大学院工学研究科（广 565-0871 大阪府吹田市山田丘 2-1)

Graduate School of Engineering,Osaka University (2-1 Yamadaoka, Suita, Osaka, 565-0871 Japan)

**大阪大学接合科学研究所 (

Joining and Welding Research Institute, Osaka University (11-1 Mihogaoka, Ibaraki, Osaka, 567-0047 Japan)

***テルモ株式会社（干 151-0072 東京都渋谷区幡ヶ谷 2-44-1）

TERUMO corporation (2-44-1 Hatagaya, Shibuya, Tokyo, 151-0072 Japan) 


\section{スマートプロセス学会誌 第 1 巻 第 6 号 (2012 年 11 月)}

\section{2. 実験方法}

本研究では、PREP 法 $^{8}$ により作製した組成比 Ti-51.19 at.\% Ni の合金粉末（純度 $99.8 \%$ 、平均粒径 $58.3 \mu \mathrm{m} 、$ FPM$\mathrm{NiTi}$ ：福田金属䈃粉工業製）を原料粉末とし、添加 $\mathrm{TiO}_{2}$ 粒 子として純度 $99.5 \%$ 、平均粒子径 $3.15 \mu \mathrm{m}$ の酸化チタン (IV) (キシダ化学製）を使用した。 $\mathrm{TiNi}$ 合金粉末および $\mathrm{TiO}_{2}$ 粒 子は、所定の混合比率 $\left(0 、 0.5 、 1.0 \mathrm{vol} . \% \mathrm{TiO}_{2}\right)$ に秤量した 後、 $\mathrm{ZrO}_{2}$ 製メディアボール $(\phi 10 \mathrm{~mm}$ 、対粉末重量比 1 : 10）と共に $\mathrm{ZrO}_{2}$ 製混合ポットに封入し、遊星ボールミル (puleverisette 5：FRITSCH 製）を用いて公転速度 $150 \mathrm{rpm}$ 、 混合時間 $18 \mathrm{ks}$ の条件にて混合処理を施した。混合時にお ける粉末酸化防止のため、混合ポット内は真空脱気後に $\mathrm{Ar}$ 雲囲気とした。得られた混合粉末は、SPS（放電プラズマ 焼結、Spark Plasma Sintering) 装置（SPS-1030S：SPS シン テックス製）を用いて、真空度 $6 \mathrm{~Pa}$ 、温度 $1173 \mathrm{~K}$ 、圧力 $40 \mathrm{MPa}$ 、保持時間 $1.8 \mathrm{ks}$ の条件にて加圧焼結し、直径 $\phi 36$ $\mathrm{mm}$ の焼結ビレットとした。その際、焼結体の寸法および 質量を測定し、試料の相対密度を算出した。この焼結体を $\mathrm{Ar}$ 䨌囲気下、温度 $1373 \mathrm{~K}$ で $600 \mathrm{~s}$ 加熱保持した後、押出比 $6 、$ 押出ラム速度 $6 \mathrm{~mm} / \mathrm{s}$ にて直ちに熱間押出加工を施した。次 に、押出材に対して $773 \mathrm{~K} に て 3.6 \mathrm{ks}$ 保持した後、直ちに 水焼入れにより急冷処理を行う形状記憶熱処理を施した。 得られた試料に対して、X 線回折（XRD-6100：島津製作所 製）による構造解析、ならびに FESEM-EDS（JSM-6500F： JOEL 製) による組織観察および元素分析を行った。力学. 形状記憶特性に関しては、押出方向に沿って採取した引張 試験片（平行部直径：3 mm、長さ：15 mm）を用いてひず み速度 $5 \times 10^{-4} \mathrm{~s}^{-1}$ にて引張試験 (AUTOGRAPH AG-X: 島津 製作所製）を実施し、また同一条件下においてヒステリシ ス試験を行い、プラトー応力および形状回復率（付与ひず み： $3 \% 、 8 \%)$ を測定した。

\section{3. 実験結果と考察}

$\mathrm{TiO}_{2}$ 粒子 1.0 vol.\%を混合した TiNi 合金粉末の EDSに よる酸素マッピング結果を Fig. 1 に示す。 $\mathrm{TiO}_{2}$ 由来の酸素 は TiNi 合金粉末表面に均一に分布しており、本混合条件に より $\mathrm{TiO}_{2}$ 粒子は凝集することなく、 $\mathrm{TiNi}$ 合金粉末表面に

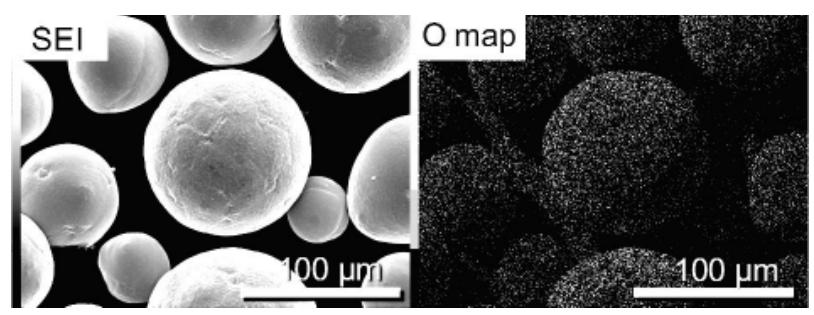

Fig. 1 EDS analysis result of TiNi pre-alloyed powder mixed with 1.0 vol. $\% \mathrm{TiO}_{2}$ particles via planetary ball mill.
均一分散したことが確認できる。 $\mathrm{TiO}_{2}$ 粒子を $0 、 1.0 \mathrm{vol} . \%$ 添加した TiNi 合金粉末を加圧焼結した SPS 焼結体断面に おける SEM 観察結果を Fig. 2 に示す。 $\mathrm{TiO}_{2}$ 粒子無添加 $(0$ vol.\% $\mathrm{TiO}_{2}$ ) の $\mathrm{TiNi}$ 合金粉末焼結体 (a) では、旧粉末の 3 重 点において空隙を起源とする未焼結部が確認でき、相対 密度（真密度 $6.45 \times 10^{3} \mathrm{~kg} / \mathrm{m}^{3}$ ) は $95.4 \%$ となった。一方、 $\mathrm{TiO}_{2}$ 粒子 1.0 vol.\% を添加した TiNi 合金粉末焼結体 (b) の 相対密度は $97.2 \%$ であり、 $\mathrm{TiO}_{2}$ 粒子添加による焼結性の低 下は確認できないことから、 $\mathrm{TiO}_{2}$ 添加粒子は $\mathrm{TiNi}$ 合金粉 末の焼結を阻害しないことが判る。また、 $\mathrm{TiO}_{2}$ 粒子を添加 した TiNi 合金粉末焼結体の旧粉末粒界には、TiNi 母相とは 異なる化合物相が観察できた。この化合物相に対して EDS による元素分析を行った結果を Fig. 3 に示す。EDSによる 線分析の結果より旧粉末粒界の化合物相は Ti、Ni および $\mathrm{O}$ から形成されていることが確認でき、焼結体に対する XRD 分析結果からこの化合物は $\mathrm{Ti}_{4} \mathrm{Ni}_{2} \mathrm{O}$ と同定した。 $\mathrm{Ti}_{4} \mathrm{Ni}_{2} \mathrm{O}$ は、 $\mathrm{TiO}_{2}$ と比較して熱力学的に安定であり、 $\mathrm{TiNi}$ と酸素が存在 した場合に生成する酸化物である ${ }^{6), 7)}$ 。そのため、同化合物 相において添加した $\mathrm{TiO}_{2}$ は検出されなかった。次に、SEM 観察像に基づいて $1.0 \mathrm{vol} \% \% \mathrm{TiO}_{2}$ 添加材の $\mathrm{Ti}_{4} \mathrm{Ni}_{2} \mathrm{O}$ 相の生成 量を測定した結果、 1.0 vol. $\% \mathrm{TiO}_{2}$ 添加材の $\mathrm{Ti}_{4} \mathrm{Ni}_{2} \mathrm{O}$ 相の生

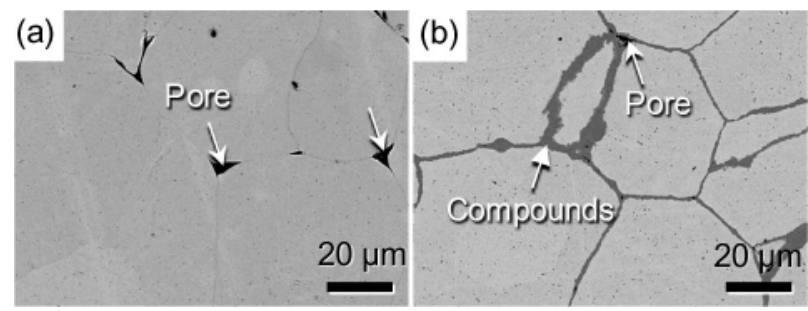

Fig. 2 SEM observation images of SPSed TiNi alloy material without $\mathrm{TiO}_{2}$ particles (a) and with $1.0 \mathrm{vol} . \% \mathrm{TiO}_{2}$ particles (b)

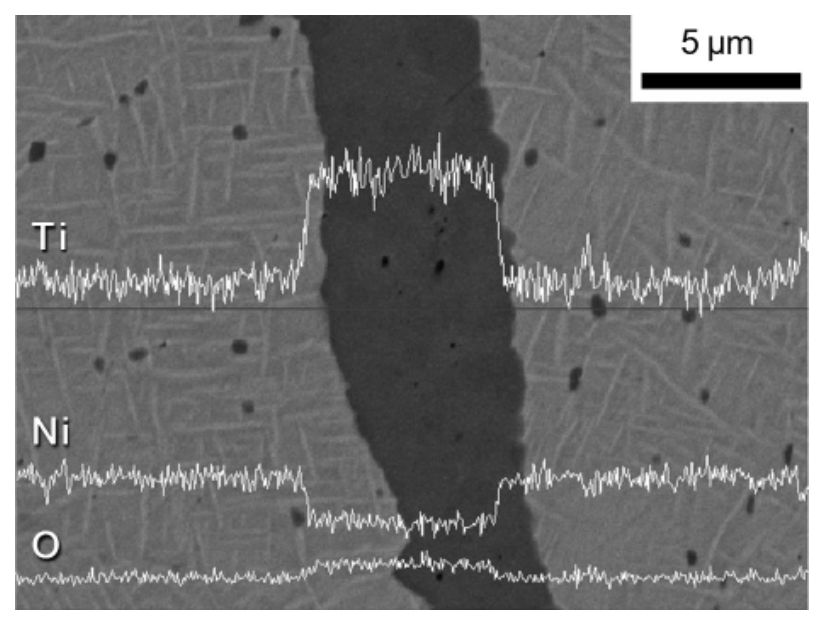

Fig. 3 EDS line analysis on primary powder boundary of SPSed TiNi alloy material with 1.0 vol. $\% \mathrm{TiO}_{2}$ particles. 
成量は 6.82 vol.\%であった。これは、 $\mathrm{TiO}_{2}$ 添加粒子がすべ て $\mathrm{Ti}_{4} \mathrm{Ni}_{2} \mathrm{O}$ 相生成に寄与すると仮定した場合の $\mathrm{Ti}_{4} \mathrm{Ni}_{2} \mathrm{O}$ 相の 生成量 $6.80 \mathrm{vol} . \%$ と良い一致を示した。以上の結果から、 旧粉末粒界の $\mathrm{Ti}_{4} \mathrm{Ni}_{2} \mathrm{O}$ 相は、 $\mathrm{TiNi}$ 合金粉末に添加した $\mathrm{TiO}_{2}$ 粒子が真空加圧・焼結工程において TiNi 母相と反応するこ とで生成したと考えられる ${ }^{9}$ 。他方、TiNi 母相では Ti-rich 組成である $\mathrm{Ti}_{4} \mathrm{Ni}_{2} \mathrm{O}$ 相の生成に伴い、固溶 $\mathrm{Ni}$ 量の増加が生 じる。混合粉末に打ける $\mathrm{Ti} 、 \mathrm{Ni} 、 \mathrm{O}$ の含有量をそれぞれ [Ti]、 [Ni]、 $[\mathrm{O}]$ とした場合、増加分を考慮した換算固溶 $\mathrm{Ni}$ 量 $\left[\mathrm{Ni}_{C}\right]$ は、次式にて計算される。

$$
\left[\mathrm{Ni}_{\mathrm{C}}\right]=\frac{[\mathrm{Ni}]-2[\mathrm{O}]}{100-7[\mathrm{O}]} \times 100
$$

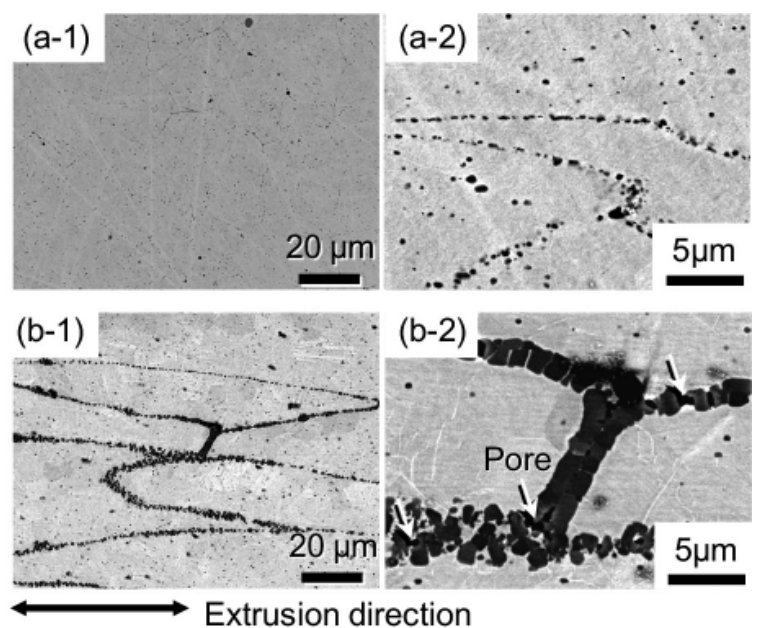

Fig. 4 SEM observation on cross-section of extruded and shape memory heat-treated TiNi alloy material without $\mathrm{TiO}_{2}$ particles (a) and with 1.0 vol. $\% \mathrm{TiO}_{2}$ particles (b).
すなわち、 0.5 vol. $\% \mathrm{TiO}_{2}$ 粒子添加材および 1.0 vol. $\% \mathrm{TiO}_{2}$ 粒子添加材に扔ける固溶 $\mathrm{Ni}$ 量の増加分は、それぞれ 0.38 at.\%、0.78 at.\% と算出できる。

次に、熱間押出加工および形状記憶熱処理を施した押出・ 形状記憶熱処理材断面の SEM 観察結果を Fig. 4 に示す。 SPS 焼結体に存在した粗大な空隙は、熱間押出加工により 閉鎖・消滅し、押出材では緻密かつ均一な組織となった。 1.0 $\mathrm{vol} . \% \mathrm{TiO}_{2}$ 粒子添加材 (b-1) においては、旧粉末粒界に生成 した $\mathrm{Ti}_{4} \mathrm{Ni}_{2} \mathrm{O}$ 相が熱間押出加工中の塑性流動により破断し、 押出方向に対して平行に分散した。また、 $\mathrm{Ti}_{4} \mathrm{Ni}_{2} \mathrm{O}$ 相と $\mathrm{TiNi}$ 母相の界面には亀裂や空隙が存在しないことから、両者の 界面整合性は良好であると判断できる。一方、 $\mathrm{Ti}_{4} \mathrm{Ni}_{2} \mathrm{O}$ 相の 内部には矢印で示すように $1 \mu \mathrm{m}$ 以下の微細な空隙 (b-2) が 存在した。これは熱間押出加工時の塑性流動による $\mathrm{Ti}_{4} \mathrm{Ni}_{2} \mathrm{O}$ 相の破断時にて生じたと考元られ、同酸化物相が脆性であ ることを示している。押出・形状記憶熱処理材を用いた引 張試験掞よびヒステリシス試験における応力ーひずみ曲線 をFig. 5 に、得られた各特性值を Table 1 に示す。な拉、 ヒステリシス試験における形状回復率 R は、ひずみ量 $3 \%$ 㧍よび $8 \%$ まで変形させた後、応力を除荷した際の残留ひ ずみを用いて算出した。 $\mathrm{TiO}_{2}$ 粒子添加により力学特性が 向上し、 1.0 vol. $\% \mathrm{TiO}_{2}$ 粒子添加材では、プラトー応力 524 $\mathrm{MPa}\left(\mathrm{TiO}_{2}\right.$ 無添加材比 $61.7 \%$ 向上)、最大応力 $1298 \mathrm{MPa}\left(\mathrm{TiO}_{2}\right.$ 無添加材比 $23.1 \%$ 向上）を示した。また、プラトー応力の 増加に伴い回復応力が向上したことで $1.0 \mathrm{vol} . \% \mathrm{TiO}_{2}$ 粒子添 加材では、ひずみ量 $8 \%$ からの形状回復率 $89.3 \%$ と優れた 形状記憶特性を示した。

$\mathrm{TiNi}$ 合金の力学・形状記憶特性は、TiNi 母相の固溶 $\mathrm{Ni}$

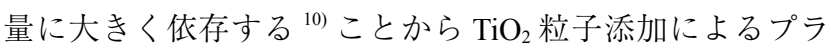
トー応力の向上は、前述した Ti-rich 組成である $\mathrm{Ti}_{4} \mathrm{Ni}_{2} \mathrm{O}$ 生 成に伴う TiNi 母相の固溶 $\mathrm{Ni}$ 量の増加に起因すると考えら
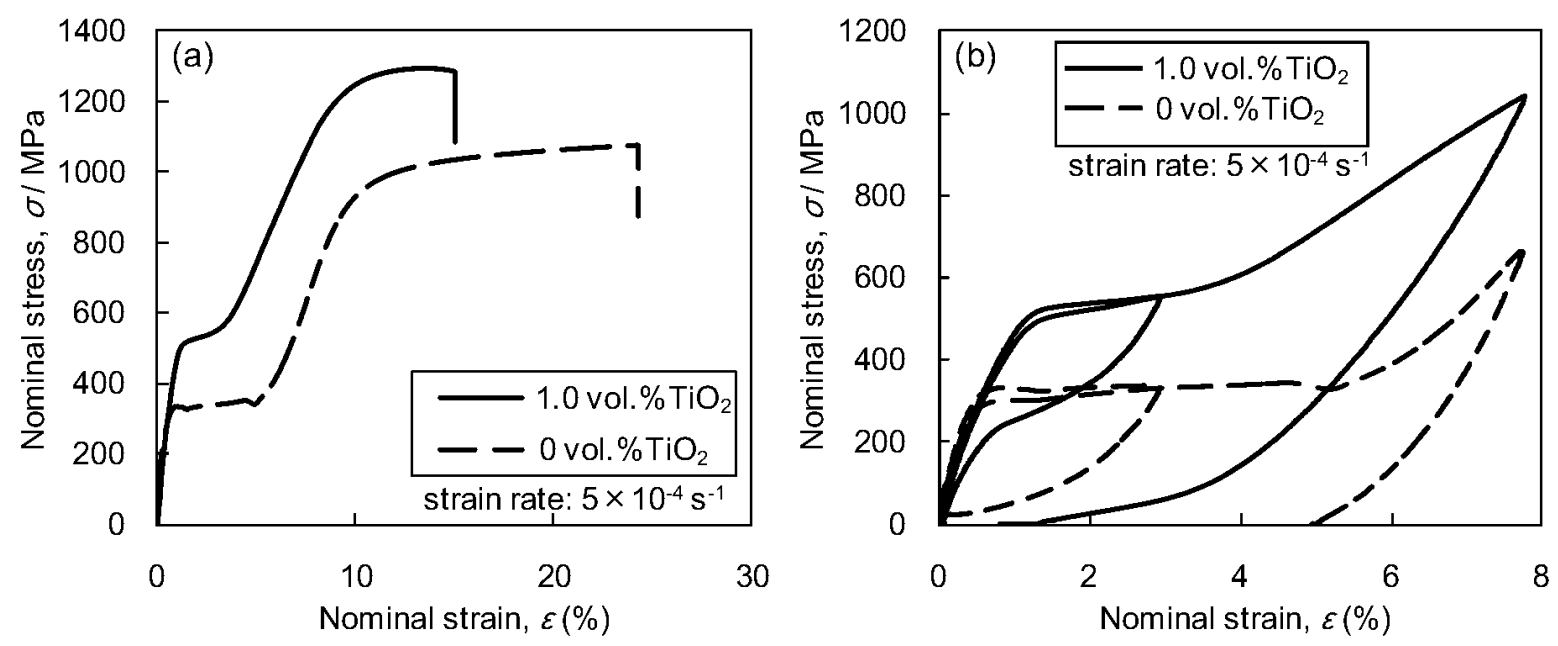

Fig.5 Tensile behavior of extruded and heat-treated TiNi alloy material with $\mathrm{TiO}_{2}$ particles in tensile test (a) and hysteresis test (b). 


$$
\text { スマートプロセス学会誌 第 } 1 \text { 巻 第 } 6 \text { 号（2012 年 } 11 \text { 月） }
$$

Table 1 Mechanical and shape memory properties of extruded and heat-treated TiNi alloy material with $\mathrm{TiO}_{2}$ particles.

\begin{tabular}{cccccc}
\hline & Plateau-Stress & UTS & Elongation & \multicolumn{2}{c}{ Recovery rate (\%) } \\
\cline { 3 - 6 } & $\mathrm{MPa}$ & $\mathrm{MPa}$ & $\%$ & $S_{T}=3 \%$ & $S_{T}=8 \%$ \\
\hline 0 vol. $\% \mathrm{TiO}_{2}$ & 324 & 1054 & 26.3 & 100 & 38.3 \\
\hline 1.0 vol. $\% \mathrm{TiO}_{2}$ & 524 & 1298 & 15.2 & 98.1 & 89.3 \\
\hline
\end{tabular}

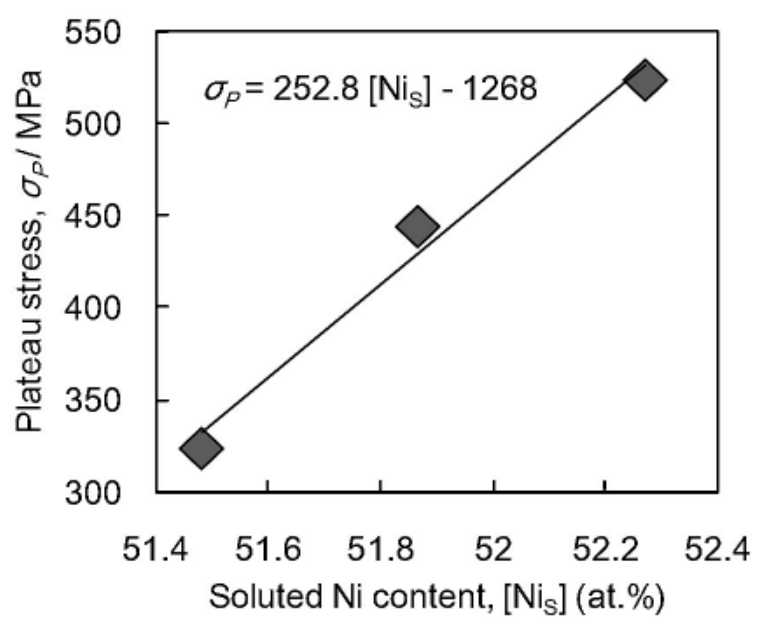

Fig. 6 Relationship between soluted Ni content in TiNi matrix and plateau stress of extruded and heat-treated TiNi alloy material with $\mathrm{TiO}_{2}$ particles.

れる。そこで、固溶 $\mathrm{Ni}$ 量の増加に伴うプラトー応力の増 加量を定量的に算出し、実験值との比較を行った。化学量 論比近傍の TiNi 合金では、マルテンサイト変態温度は固溶 $\mathrm{Ni}$ 量の増加とともに線形的に低下し、単位固溶 $\mathrm{Ni}$ 量あた りの低下量はー85.37 K/at.\%Ni を示す ${ }^{7)}$ 。その際、マルテン サイト変態温度が $\Delta M_{S}$ だけ変化した際のプラトー応力の変 化量 $\Delta \sigma_{p}$ は、 TiNi 母相とマルテンサイト相の Gibbs 自由エ ネルギーの関係から次式で表される ${ }^{11)}$

$$
\Delta \sigma_{p}=\frac{\Delta S}{\gamma V_{M}} \Delta M_{S}
$$

ここで、 $\Delta S 、 \gamma 、 V_{M}$ はそれぞれ変態エントロピ、変態ひずみ、 モル体積であり、 $\Delta S / \gamma V_{M}=-3.03 \mathrm{MPa} / \mathrm{K}$ とする ${ }^{10), 12)}$ 。上式 より、単位固溶 $\mathrm{Ni}$ 量あたりのプラトー応力の増加量は 256 $\mathrm{MPa} / \mathrm{at} . \% \mathrm{Ni}$ となる。次に、本研究で作製した試料において、 前出の (1) 式より算出した換算固溶 $\mathrm{Ni}$ 量に基づいて得られ たプラトー応力と固溶 $\mathrm{Ni}$ 量の関係を Fig. 6 に示す。両者 は 1 本の線形近似式にて整理され、その傾きは $253 \mathrm{MPa} /$ at.\%Ni となった。この傾きは、先の理論式 (2) を用いて算 出した増加分 $256 \mathrm{MPa} / \mathrm{at} \% \mathrm{Ni}$ と良い一致を示しており、プ ラトー応力増加の主要因は、 $\mathrm{Ti}_{4} \mathrm{Ni}_{2} \mathrm{O}$ 生成に伴う $\mathrm{TiNi}$ 母相 における固溶 $\mathrm{Ni}$ 量の増加であるといえる。

\section{4. 結 論}

本研究では、塑性加工・熱処理履歴に依存しない TiNi 形 状記憶合金の高機能化に関する新たな材料設計手法の確立 を目的に、粉末治金法を用いて $\mathrm{TiO}_{2}$ 粒子添加 $\mathrm{TiNi}$ 合金粉 末焼結押出材を作製した。作製したTiNi 合金に対して、組 織構造解析ならびに力学・形状記憶特性評価を実施した。 本調査によって得られた知見を以下に示す。

(1) $\mathrm{TiNi}$ 合金粉末に添加した $\mathrm{TiO}_{2}$ 粒子は、SPS 焼結過程に おいて Ti と O に分解し、TiNi 母相と反応することで旧 粉末粒界に $\mathrm{Ti}_{4} \mathrm{Ni}_{2} \mathrm{O}$ 相を生成した。また、Ti-rich 組成で ある $\mathrm{Ti}_{4} \mathrm{Ni}_{2} \mathrm{O}$ 相の生成に伴い $\mathrm{TiNi}$ 母相の固溶 $\mathrm{Ni}$ 量が増 加した。

(2) $\mathrm{TiO}_{2}$ 粒子の添加により $\mathrm{TiNi}$ 合金の力学・形状記憶特 性は向上し、熱間押出・形状記憶熱処理を施した 1.0 vol. $\% \mathrm{TiO}_{2}$ 粒子添加材では、プラトー応力 $524 \mathrm{MPa}$ 、最

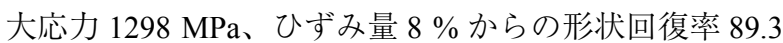
$\%$ と優れた力学・形状記憶特性を発現した。

(3) プラトー応力は、 $\mathrm{Ti}_{4} \mathrm{Ni}_{2} \mathrm{O}$ 相の生成に伴う固溶 $\mathrm{Ni}$ 量の増 加を考慮した換算固溶 $\mathrm{Ni}$ 量に比例した線形近似式とし て整理された。また、TiNi 母相の固溶 $\mathrm{Ni}$ 量とマルテン サイト変態温度、ならびにプラトー応力の関係式を用 いてプラトー応力の増加分を定量的に評価した。

以上の結果から、粉末治金法を用いた $\mathrm{TiO}_{2}$ 粒子の添加に よって TiNi 母相の組成比を間接的に制御でき、塑性加工・ 熱処理による従前手法と異なる材料設計に基づいて、TiNi 形状記憶合金の高強度・高回復率の実現が可能となること を明らかにした。

\section{謝 辞}

本研究にて使用した TiNi 合金粉末は、テルモ株式会社か らの提供によるものであり、ここに謝意を表する。なお、 本研究の一部は、近畿経済産業局長・戦略的基盤技術高度 化支援事業(平成 $22 ２ 4$ 年度)により実施したものである。

\section{参考文献}

1) 戸伏尋昭、田中喜久昭、堀川宏、松本實、“形状記憶材料とそ の応用”、(2004), コロナ社 .

2) J. K. Allafi, B. A. Ahmadi, M. Zare, Materials Science and Engineering C, Vol. 30 (2010) pp. 1112-1117. 
$\mathrm{TiO}_{2}$ 粒子を添加した高強度 $\mathrm{TiNi}$ 形状記憶粉末合金の組織構造と力学特性（米澤・吉村・梅田・近藤・早場）

3) P. Filip, J. Lausmaa, J. Musialek, K. Mazanec, Biomaterials, Vol. 22 (2001) pp. 2131-2138.

4) 大方一三、“形状記憶合金の医療への応用”、日本機械学会誌、 Vol. 107 (2004) pp. 532-535.

5) D. Vojtěcha, M. Voděrováa, J. Kubáseka, P. Nováka, P. Šedáa, A. Michalcováa, J. Fojta, O. Mestekc, Materials Science and Engineering A, Vol. 528 (2011) pp. 1864-1876.

6) 上原重昭、笹野久興、吉岡孝之、本間一広、鈴木敏之、粉体 および粉末治金、Vol.33 (1986) pp. 17-21

7) 守護嘉朗、花田修治、本間敏夫、東北大學選鑛製錬研究所彙報、 Vol. 41 (1985) pp. 23-34.
8) Leo. V. M. Antony, R. G. Reddy, JOM JOURNAL OF THE MINERALS, Vol. 55 (2003) pp. 14-18.

9) K. Kondoh, T. Mimoto, N. Nakanishi, J. Umeda, 3rd Asian Symposium on Materials and Processing (ASMP2012), 48, Chennai, India, (Aug. 30-31, 2012)

10) K. Otsuka, X. Ren, Progress in Materials Science, Vol. 50 (2005) pp. 511-678.

11) M. Kato, H-R. Pak, physica status solidi (b), Vol. 123 (1984) pp. 415-424.

12) W. Tang, MetalluRgical AND MATERIALS TRANSACTIONS A, Vol. 28 (1997) pp. 537-544. 